\title{
Assessing Flow Response of Self-compacting Mortar by Taguchi Method and ANOVA Interaction
}

\author{
Abhijit Chatterjee, Debashis Das* \\ Material and Structural Evaluation Group, Central Mechanical Engineering Research \\ Institute - CSIR-CMERI, Mahatma Gandhi Avenue, P.O.-Durgapur-713209, West Bengal, India
}

Received: October 1, 2012; Revised: March 5, 2013

\begin{abstract}
Self-compacting mortar (SCM) is a new generation product and has prospective use as an independent material as well as an integral constituent of self-compacting concrete (SCC). In this paper the flow response of self-compacting mortar is assessed by Taguchi method and ANOVA interaction. Effect of powder material and super-plasticizer on the relative flow index of fresh SCM is evaluated by mortar trial test designed by Taguchi method of optimization. An ANOVA interaction analysis is performed to comprehend the interaction of the factors and their effect on quality characteristic. The relative significance level of powder material and super-plasticizer in governing the flow characteristic is discussed. A modified approach is proposed by incorporation of the error balancing property of statistical central tendency and the assumption of non- variance of mean. Construing contribution of mean, sample size and relative error to Signal to Noise Ratio provides limits of deviations of the same.
\end{abstract}

Keywords: self-compacting mortar, relative flow value, quality characteristics, taguchi method, signal to noise ratio

\section{Introduction}

When developing self-compacting concrete mix the flowability is one of the primary requirements for the mix to qualify as a SCC mix. Although there are several qualifying tests of fresh $\mathrm{SCC}^{1}$ a preliminary idea for initializing the powder and super-plasticizer content is required to achieve the desired response during the initial trial of SCC. The fundamental study of flowability of self-compacting concrete was carried out in Japan in the later period of eighties $^{2}$. A few guidelines on mix composition and testing procedures are available ${ }^{3,4}$. Mortar trial test ${ }^{1,5,2}$ provides an initial testing procedure to get an estimate of the flow behavior of the self-compacting concrete in reference to the flow behavior of the mortar only. A considerable body of research exists for normally compacting $\operatorname{mortar}^{6-9}$. But the significance of self-compacting mortar lies in its influence in controlling the quality characteristics of self-compacting concrete in fresh state.

The difference of self-compacting concrete and normally compacted concrete is attributed to mix constituent and fresh properties of $\mathrm{SCC}^{10}$. Again fresh properties of SCC can be attributed to a great extent to the fresh properties of mortar (powder, fine aggregate, water, and admixture). The flow characteristics of mortar is dependent on several factors including powder content and dose of super-plasticizer for a given water powder ratio ${ }^{11-13}$. But uncontrolled employment of super-plasticizer and powder may lead to unsatisfactory flow behavior in association with higher risk of segregation. Static segregation is mainly controlled by gravitational force. Dynamic segregation depends on flow rate and frictional forces (restrictions in formwork, floor, etc.). Thus analytical

*e-mail: cmericivil@gmail.com procedure is required to quantify the experimental output for identifying the most expected combination and the corresponding response. Use of Taguchi method to analyze effect of admixture in concrete mix design has been reported by researchers ${ }^{14,15}$. Optimization of the mix proportion of the fly ash brick by Taguchi method of parameter design was reported by a few researchers ${ }^{16}$.

In this paper the Taguchi method is applied to analyze the effect of content of powder and super-plasticizer on flow characteristic of self-compacting mortar. An ANOVA interaction analysis is also performed to understand the significance of relative inter-dependence of powder and super-plasticizer in controlling optimum flow behavior. A modified approach is proposed for controlled and limited trial experimentation.

\section{Characteristics of Material}

The mortar was developed using OPC 43 Grade cement and a flyash with low calcium content sourced from a super Thermal Power Plant. The physical properties of cement are given in (Table 1). The physical and chemical characteristics of the other two powder materials (flyash and microsilica) are shown in (Table 2) $)^{17,18}$. A commercially available poly-carboxylic ether based super-plasticizer with specific gravity 1.1 was used ${ }^{19,20}$. The super-plasticizer was light brown in appearance with a alkali content of less than $1 \%$. The maximum value of chloride content was $0.1 \%$. The super-plasticizer had a suggested dosage of 0.185 to 1.111 liters per $100 \mathrm{~kg}$ of material (binder and fillers passing the $0.1 \mathrm{~mm}$ sieve). However suitable dosage depends on site conditions, type of concrete, materials used, etc. The 
super-plasticizer was used at ambient temperature above $15^{\circ} \mathrm{C}$. The rapid adsorption mechanism of super-plasticizer molecules onto the cement particles provides an efficient dispersion effect. The dispersive effect of super-plasticizer is related with the tri- Calcium Aluminate $\left(\mathrm{C}_{3} \mathrm{~A}\right)$ and alkali content of cement, and fineness of cement. Dose and the method of addition of super-plasticizer is also important for initial dispersive effect. A water powder ratio of 0.32 was selected for this investigation. The cement content and flyash content was in equal proportion (1:1), 50\% each. SCC mixtures with high volume flyash content, 40 to $60 \%$, are reported in literature ${ }^{13} .5 \%$ silica fume by weight of cement was added to the mix. It is found that fineness of flyash particles was higher than cement particles and fineness of silica fume particles was much higher than cement and flyash particles (Tables 1 and 2). As a result flyash particles fill the voids of cement particles. The workability is enhanced due to the spherical shape of flyash particles which reduces the inter particle friction due to ball bearing effect. The silica fume particles being the finest enters the voids of the flyash particles and reduces the tendency to segregation and bleeding. It is reported in literature that incorporation of micro-silica with flyash improved the flow ability of mortars in general $^{12}$. Thus a powder consisted of cement, flyash and silica fume is essential for desirable SCM properties. Self compacting mortar (SCM) is an integral part of self compacting concrete. SCC has lower percentage of coarse aggregate compared to conventional concrete. The properties of SCM play a dominant role in governing the properties of SCC. Hence the proportions are chosen for SCM in this paper which is part of a larger test programme on SCC.

Mortar flow test was executed following EFNARC guidelines to determine the dose of super-plasticizer required to achieve the desired flow characteristics. The relative flow value $\left(\Gamma_{\mathrm{m}}\right)$ indicates the flowability of the mortar. The relative flow index $\left(\Gamma_{\mathrm{m}}\right)$ is a unit less parameter which is equal to one less than the squared of the ratio of flow diameter to the initial diameter of the base of the cone.

A rotating tilting drum type mixer was used (IS 1791, 1985) ${ }^{21}$. Mixing order of ingredients influences the fresh properties of self compacting mortar (SCM $)^{22}$. Out of different mixing order tried a particular mixing order was selected for preparation of mortar mix. Initially cement, flyash and silica fume was put in the mixer in a dry state and mixing was carried out for 1 minute. Then one fifth of total water and one third of super-plasticizer were added gradually during mixing for a period of half minute. Fine aggregate was added to this mix and the mixing was carried out for another half minute. After that the remaining water and super-plasticizer was added slowly. Mixing was continued for two more minutes including the time taken for addition of super-plasticizer. The mix was inspected visually and mixing was stopped if found adequate. The water used for mixing was free from deleterious materials. Potable water with a temperature of $27 \pm 2{ }^{\circ} \mathrm{C}$ was used in mixing.

\section{Design of Experiment}

The orthogonal array concept is the key to the experimental design. The purpose is to effectively design the effects of multiple process parameters on the flow characteristics of self-compacting mortar. For the present investigation the control factors and levels are given in (Table 3). The levels for control factor A (powder to fine aggregate ratio) were increased from 1:1.04 to 1:2.21 at a step of 0.39 . The basic ratios are selected in a larger context of a test programme on self compacting concrete (SCC) which is not a part of this paper ${ }^{10}$. The range selected

Table 1. Physical Properties of Cement.

\begin{tabular}{lccc}
\multicolumn{1}{c}{ Characteristics } & Units & Results Obtained & $\begin{array}{c}\text { Specified Value as } \\
\text { Per IS:8112-1989 }\end{array}$ \\
\hline Blaine 's fineness & & 3048 & $3500($ maximum) \\
Specific gravity & $\mathrm{cm}^{2} / \mathrm{gm}$ & 3.14 & $\ldots$ \\
Soundness (Le Chatelier test) & $\ldots$ & 2.1 & $10($ maximum) \\
Autoclave expansion & $\mathrm{mm}$ & 0.71 & $0.8($ maximum) \\
Normal consistency (Percent of cement by weight) & $\%$ & 27 & 30 \\
Setting time & & & $30($ minimum) \\
(i) Initial & minutes & 180 & $600($ maximum) \\
(ii) Final & & & \\
Compressive strength & & 25.8 & 23.0 \\
(i) 3 days & MPa & 35.0 & 33.0 \\
(ii) 7 - days & & 44.3 & 43.0 \\
(iii) $28-$ days & & & \\
\hline
\end{tabular}

Table 2. Physical and Chemical Properties of Flyash and Micro - silica.

\begin{tabular}{clcc}
\hline No. & \multicolumn{1}{c}{ Property } & Flyash & Micro - silica \\
\hline 1. & Blaine 's fineness, $\mathrm{cm}^{2} / \mathrm{gm}$ & 3500 & 22000 \\
2. & Specific gravity & 2.24 & 2.20 \\
3. & Silicon dioxide, $\mathrm{SiO}_{2}$, percent by mass & 57.5 & 95.1 \\
4. & $\mathrm{SiO}_{2}+\mathrm{Al}_{2} \mathrm{O}_{3}+\mathrm{Fe}_{2} \mathrm{O}_{3}$, by mass & 91.0 & 95.1 \\
5. & Loss on ignition, percent by mass & 0.57 & 2.79 \\
\hline
\end{tabular}


serves the purpose of testing SCM as a component of SCC. For control factor B (super-plasticizer to powder ratio) dose is increased from 1 to $2.5 \%$ at a step of $0.5 \%$. The dose is selected considering the requirement of SCC. An L16 standard orthogonal array as shown in (Table 4) was employed for the present investigation. The layout of the experimental design is described in (Table 5). In the Taguchi method the signal to noise ratio is used to consolidate a number of repeated values into a single value which is the representation of the existing variation in the data. In the present trials the "higher is better" criteria is employed for computing S/N ratio of the flow characteristics of mortar. An analysis of variance (ANOVA) interaction test was performed to understand the interaction effect of the two factor parameter (Table 4).

\section{Results and Discussion}

\subsection{Effect of powder to fine aggregate ratio on relative flow of self-compacting mortar}

Self-Compacting mortar has higher content of powder materials to achieve the desired relative flow value. The mortar is a combination of powder, fine aggregate, admixture and water. The efficiency of the mortar mix depends on the synchronous flow behavior of all the ingredients of mortar during the mortar trial test. It is significant for self-compacting mortar due to the unique property of flowability which requires non separation of paste and water. Addition of super- plasticizer initiates electrostatic dispersion mechanism. But unlike other types of super-plasticizers polycarboxylic ether based super-plasticizer have side chains linked to the polymer backbone which generates a steric hindrance ${ }^{23,24}$. It ultimately helps in stabilization of cement particle's ability to separate and disperse. It helps to maintain concrete flowability even with reduced water content. Results of the mortar trial test and calculated signal to noise ratios are shown in (Table 6). The ANOVA analysis (Table 7) indicates very significant effect of powder to fine aggregate ratio on the relative flow value of self-compacting mortar under consideration. The highest signal to noise ratio evaluated for powder content is found for factor level-1 (96.15\%).

This is followed by factor level 2, 3 and 4 respectively (Figure 1). Thus the desired powder content is $96.15 \%$ of fine aggregate for optimum relative flow value. There is negligible change in the signal to noise ratio for factor level 1, 2 and 3. But a sharp drop in the signal to noise ratio is observed for factor level 4 (Figure 1). This implies that reduction of powder content beyond factor level 3 is undesirable. Thus a minimum powder to fine aggregate ratio of $54.95 \%$ should be maintained to achieve the expected flow behavior. Any drop in powder content below $55 \%$ will result in abrupt fall in the relative flow value causing non uniform flow, slower spread and higher tendency to bleeding.

A considerable body of research on $\mathrm{SCC}^{13}$ (flyash content 40 to $60 \%$, water powder ratio 0.35 to 0.5 ) reported that for a fine aggregate to powder ratio lying between 45 to $49 \%$ flowability of SCC varied extensively. However

Table 3. Control Factors and Levels.

\begin{tabular}{lccccc}
\hline \multirow{2}{*}{$\begin{array}{c}\text { Process Parameter } \\
\text { (Factor) }\end{array}$} & \multirow{2}{*}{ Designation } & \multicolumn{4}{c}{ Levels } \\
\cline { 3 - 6 } & & & \multicolumn{3}{c}{ Level 1 Level 2 Level 3 Level 4 } \\
\hline Powder (Cement +Flyash+ silica fume) to & \multirow{2}{*}{ A } & $96.15 \%$ & $69.93 \%$ & $54.95 \%$ & $45.25 \%$ \\
Fine Aggregate Ratio (in \%) & & $(1: 1.04)$ & $(1: 1.43)$ & $(1: 1.82)$ & $(1: 2.21)$ \\
\hline Super-plasticizer to Powder Ratio (\%) & B & $1 \%$ & $1.5 \%$ & $2 \%$ & $2.5 \%$ \\
\hline
\end{tabular}

cement : flyash $=1: 1$ by weight, $5 \%$ silica fume by weight of cement.

Table 4. Standard Orthogonal Array L16.

\begin{tabular}{cccc}
\hline Exp No & Factor A & Factor B & Factor AXB \\
\hline 1 & 1 & 1 & 1 \\
2 & 1 & 2 & 2 \\
3 & 1 & 3 & 3 \\
4 & 1 & 4 & 4 \\
5 & 2 & 1 & 2 \\
6 & 2 & 2 & 1 \\
7 & 2 & 3 & 4 \\
8 & 2 & 4 & 3 \\
9 & 3 & 1 & 3 \\
10 & 3 & 2 & 4 \\
11 & 3 & 3 & 1 \\
12 & 3 & 4 & 2 \\
13 & 4 & 1 & 4 \\
14 & 4 & 2 & 3 \\
15 & 4 & 3 & 2 \\
16 & 4 & 4 & 1 \\
\hline
\end{tabular}

Table 5. Layout of Design of Experiment.

\begin{tabular}{ccc}
\hline Exp No & Factor A & Factor B \\
\hline 1 & 96.15 & 0.01 \\
2 & 96.15 & 0.015 \\
3 & 96.15 & 0.02 \\
4 & 96.15 & 0.025 \\
5 & 69.93 & 0.01 \\
6 & 69.93 & 0.015 \\
7 & 69.93 & 0.02 \\
8 & 69.93 & 0.025 \\
9 & 54.95 & 0.01 \\
10 & 54.95 & 0.015 \\
11 & 54.95 & 0.02 \\
12 & 54.95 & 0.025 \\
13 & 45.25 & 0.01 \\
14 & 45.25 & 0.015 \\
15 & 45.25 & 0.02 \\
16 & 45.25 & 0.025 \\
\hline
\end{tabular}


the best flowability was obtained for two mixes. One mix had a flyash content of $50 \%$ and water powder ratio of 0.35 . It achieved the best flowability (funnel test time $6 \mathrm{sec}$ ) for a powder to fine aggregate ratio of $46.03 \%$. The second mix with $40 \%$ flyash content and the same water powder ratio (0.35) achieved similar flowability with a powder to fine aggregate ratio of $45 \%$. Thus minimum powder content of $55 \%$ (as percentage of fine aggregate) obtained in the present investigation (water powder ratio 0.32 ) by Taguchi method provides the lower limit of powder content for the specific materials used and also reveals that scope to achieve self

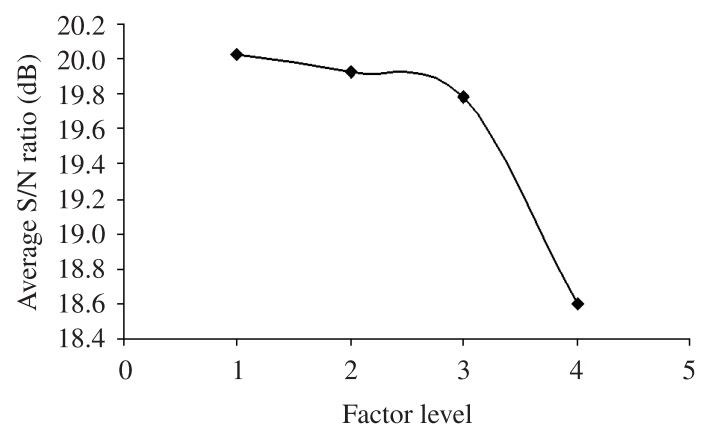

Figure 1. Average $\mathrm{S} / \mathrm{N}$ ratio for powder to Fine aggregate ratio. compatibility of mortar even with a very high powder to fine aggregate ratio has promising potential.

\subsection{Effect of super-plasticizer on relative flow of self-compacting mortar}

The molecular configuration of the super-plasticizer retards the cement hydration ${ }^{11}$. Among various types of super-plasticizers a modified polycarboxylate based super-plasticizer was used in the mortar mix. This new generation super-plasticizer provided improved workability to $\mathrm{SCM}^{11}$. Rapid adsorption of the molecules onto the powder particles aided by efficient dispersion effect exposes increased surface of the cement and flyash grains to interact with water. The dose of super-plasticizer is the key parameter enabling the powder paste to flow. The efficiency of the superplasticizer in the mortar depends upon the powder content. Thus super-plasticizer to powder ratio is highly significant (more than the powder to fine aggregate ratio) in governing the relative flow value of self-compacting mortar (Table 7). The very high F-ratio (2 621.9) as compared to the critical F-ratio value (2.83) emphasizes the importance of superplasticizer to powder ratio. The optimum factor level is found as factor level 4 which has the highest signal to noise ratio (Figure 2). Thus $2.5 \%$ of super-plasticizer to powder ratio gives the optimum results. But understanding of the physical

Table 6. Results (Relative Flow Value).

\begin{tabular}{cccccc}
\hline Experiment No & Reading 1 & Reading 2 & Reading3 & Mean & S/N Ratio (dB) \\
\hline 1 & 5.1 & 5.0 & 5.5 & 5.2 & 14.29 \\
2 & 9.1 & 9.8 & 9.3 & 9.4 & 19.45 \\
3 & 11.9 & 11.8 & 12.3 & 12.0 & 21.58 \\
4 & 17.2 & 17.4 & 17.30 & 17.3 & 24.76 \\
5 & 4.99 & 5.04 & 5.00 & 5.01 & 13.99 \\
6 & 9.30 & 9.4 & 9.5 & 9.4 & 19.46 \\
7 & 11.7 & 11.9 & 12.4 & 17.0 & 21.57 \\
8 & 17.0 & 17.1 & 17.2 & 5.0 & 24.66 \\
9 & 4.9 & 4.9 & 5.2 & 9.0 & 13.97 \\
10 & 8.9 & 9.3 & 8.8 & 11.85 & 19.07 \\
11 & 11.8 & 12.05 & 11.7 & 17.0 & 21.47 \\
12 & 16.7 & 17.1 & 17.2 & 4.2 & 24.61 \\
13 & 4.0 & 4.1 & 4.5 & 8.3 & 12.43 \\
14 & 8.1 & 8.3 & 8.5 & 10.0 & 18.38 \\
16 & 9.8 & 9.9 & 10.3 & 15.1 & 19.99 \\
\hline
\end{tabular}

Table 7. Analysis of variance (ANOVA) for Relative flow value.

\begin{tabular}{lccccccc}
\hline \multicolumn{1}{c}{ Factor } & $\begin{array}{c}\text { Sum of } \\
\text { squares (S) }\end{array}$ & $\begin{array}{c}\text { Degree of } \\
\text { freedom }\end{array}$ & $\begin{array}{c}\text { Variance } \\
(\mathbf{V})\end{array}$ & F-ratio & $\begin{array}{c}\text { Pure sum } \\
\text { of squares } \\
(\mathbf{S})\end{array}$ & $\begin{array}{c}\text { Percent } \\
\text { contribution } \\
\text { (P) }(\%)\end{array}$ & $\begin{array}{c}\text { Remarks } \\
\text { Critical F-value at } \\
\mathbf{9 5 \%} \text { confidence } \\
\text { level is 2.83 }\end{array}$ \\
\hline $\begin{array}{l}\text { Powder(Cement+Flyash+ } \\
\text { silica fume) to Fine } \\
\text { Aggregate Ratio (in \%) }\end{array}$ & 19.47 & 3 & 6.49 & 58.68 & 19.14 & 2.14 & significant \\
\hline $\begin{array}{l}\text { Super-plasticizer } \\
\text { to Powder Ratio }\end{array}$ & 870.14 & 3 & 290.05 & 2621.97 & 869.81 & 97.27 & $\begin{array}{c}\text { Highly } \\
\text { significant }\end{array}$ \\
\hline Other/errors & 4.54 & 41 & 0.1106 & $\ldots$ & 5.19 & 0.58 & \\
\hline Total & 894.15 & 47 & $\ldots$ & $\ldots$ & 894.15 & 100 & \\
\hline
\end{tabular}


characteristics of mortar differs from the mathematical extract. For a super-plasticizer to powder ratio of $1 \%$ uniform flow is obtained but the corresponding V-Funnel flow rate is more than acceptable value ( 7 seconds). For $2 \%$ of the same ratio uniform flow was observed with slight tendency to bleeding. For $2.5 \%$ of the same separation of paste and water was observed. Hence these ratios of super-plasticizer to powder results in unacceptable mortar property. But at $1.5 \%$ of the ratio uniform flow, quick spread and non existence of bleeding was observed, satisfying the requirement of flowable mortar behavior. Study on effect of super-plasticizer and mineral admixtures on flowability of SCC reported in literature reveals similar trend ${ }^{13}$. Methodology for mix design of mortar in binary blends of powder to achieve adequate flow properties is reported in literature ${ }^{25}$. Thus the output of the optimization process is accepted only after analyzing the other physical requirements.

Thus the optimum flow behavior (relative flow value) is suggested for a powder to fine aggregate ratio of $96.15 \%$ and a super-plasticizer to powder ratio of $1.5 \%$ satisfying the basic requirement of self-compacting mortar.

An important step in this optimization procedure is to validate the estimated results through confirmation test. Confirmation test at the optimum settings of the process parameters is a tool to verify that the mean response factor falls within the predicted $95 \%$ confidence interval. The values of the predicted optimum relative flow falls within the predicted range as obtained from the confirmation test (Table 8).

\subsection{Analysis of variance interaction on relative flow test results}

In the previous sub-sections individual effects of powder to fine aggregate ratio and super-plasticizer to powder ratio on the relative flow index are discussed. But the practical requirement is that satisfaction of individual criteria for factors does not necessarily reveals any contradicting or favorable effect of one factor upon another. Basic understanding of the action of super-plasticizer in mortar suggests that the dose of super-plasticizer is also

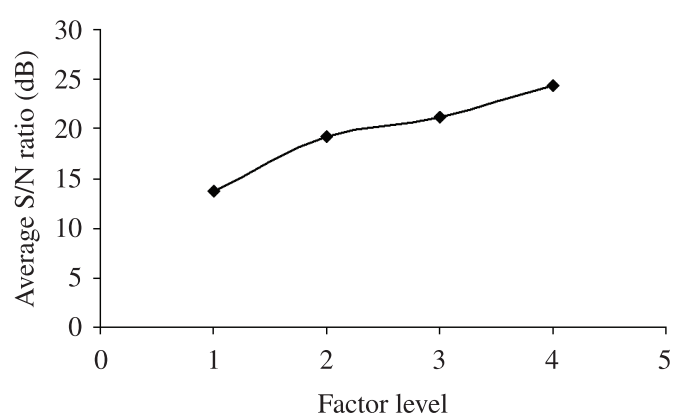

Figure 2. Average S/N ratio for Super-plasticizer to powder ratio. dependent on the powder content and thus cannot be treated as an independent governing factor. The super-plasticizer molecules get adsorbed on to the powder particles and repel each other. As a result the relative flow value increases. Thus any increase in powder content influences the degree of flowability for desired super-plasticizer content.

Any such physical phenomenon can be studied through analysis of variance interaction which expresses the degree of significance of the two factors while acting in synergy. The F-ratio of the interaction effect of the two factors, powder to fine aggregate ratio and super-plasticizer to powder ratio (5.435) is higher than the critical F-value at $95 \%$ confidence level (2.9) and the critical F-value for interaction (2.19) (Table 9). It implies that factor A has significant effect on factor B or vice-versa.

The percent contribution of super-plasticizer to powder ratio $(97.30 \%)$ dominates over the percent contribution of powder to fine aggregate ratio $(2.16 \%)$ and the interaction of the factors $(0.25 \%)$. It implies that super-plasticizer to powder ratio has the greatest contribution in controlling the relative flow value.

The graphical representation of the interaction effect (Figure 3) between the factors facilitates the choice of factor and the corresponding level for a desired flow characteristic.

\section{A Modified Approach}

The best combination of factor parameter and level is determined based on the signal to noise ratio. The signal to noise ratio is again dependent on the individual readings. For the same mean value of the readings there exist many possible arrays of individual readings obtained by the change of experimental conditions. The variation in the readings depends on the control condition at different stages of mixing, placing, instrumental accuracy and manual efficiency. Thus the inherent uncertainty of material, process, machine and human error affects the readings and in turn the signal to noise ratios. But the optimum settings of the process parameters are not expected to vary with imposed or natural error of any category. Again the $\mathrm{S} / \mathrm{N}$ ratio of optimum setting cannot vary with number of readings as well. It implies that any higher uncertainty during the experimentation may significantly alter the optimum setting which is not desired. To reduce this effect of experimental uncertainty on the signal to noise ratio a modified approach is proposed here.

The mean value expresses an important central tendency which balances the errors. Thus evaluation of signal to noise ratio based on the mean value considerably expels the errors and becomes independent of the variation of individual readings. The following equation is used to calculate the signal to noise ratio for higher is better criteria.

$$
S / N=-10 \log \left[\left(\frac{1}{n}\right) \sum_{i, j=1}^{n} \frac{1}{y_{i j}^{2}}\right]
$$

Table 8. Confirmation test of the results.

\begin{tabular}{cccc}
\hline Result & $\begin{array}{c}\text { Prediction of Optimum } \\
\text { Quality Characteristic }\end{array}$ & Range & Experimental Value \\
\hline 1) Relative flow value (optimum level A1,B4) & 17.12 & 16.64 to 17.57 & 17.3 \\
2) Relative flow value (optimum level A1,B2) & 9.5 & 9.04 to 9.97 & 9.4 \\
\hline
\end{tabular}


Table 9. Analysis of variance Interaction (ANOVA) for Relative flow value.

\begin{tabular}{lccccccc}
\hline \multicolumn{1}{c}{ Factor } & $\begin{array}{c}\text { Sum of } \\
\text { squares (S) }\end{array}$ & $\begin{array}{c}\text { Degree of } \\
\text { freedom }\end{array}$ & $\begin{array}{c}\text { Variance } \\
(\mathbf{V})\end{array}$ & F-ratio & $\begin{array}{c}\text { Pure sum of } \\
\text { squares (S) }\end{array}$ & $\begin{array}{c}\text { Contribution } \\
\text { ratio (P) }(\%)\end{array}$ & Remarks \\
\hline $\begin{array}{l}\text { Powder (Cement +Flyash+ } \\
\text { silica fume) to Fine Aggregate }\end{array}$ & 19.47 & 3 & 6.49 & 117.61 & 19.31 & 2.16 & significant \\
$\begin{array}{l}\text { Ratio (in \%) } \\
\begin{array}{l}\text { Super-plasticizer } \\
\text { to Powder Ratio }\end{array}\end{array}$ & 870.14 & 3 & 290.04 & 5254.46 & 869.97 & 97.30 & Highly \\
AXB & 2.77 & 9 & 0.30 & 5.43 & 2.27 & 0.25 & Significant \\
$\begin{array}{l}\text { Other/errors } \\
\text { Total }\end{array}$ & 1.76 & 32 & 0.05 & $\ldots$ & 2.59 & 0.29 & \\
\hline
\end{tabular}

$(\mathrm{F} 0.05,9,32=2.19$ and F0.05,3,32 = 2.9).

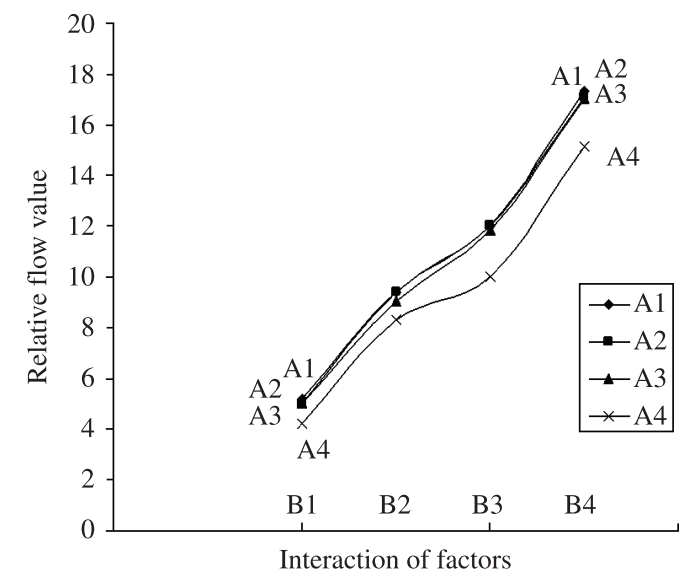

Figure 3. Response of interaction.

$S / N=-10 \log \left[\left(\frac{1}{n}\right) \sum_{i, j=1}^{n} \frac{1}{\left(\mu+\xi_{i j}\right)^{2}}\right]$

Where $\xi_{\mathrm{ij}}$ is the error of $\mathrm{i}$ th trial of $\mathrm{j}$ th reading with respect to the mean $(\mu)$ of $i$ th trial.

$S / N=-10 \log \left[\left(\frac{1}{n}\right) \sum_{i, j=1}^{n} \frac{1}{\left(1+\frac{\xi_{i j}}{\mu}\right)^{2}\left(\mu^{2}\right)}\right]$

$S / N=-10 \log \left[\left(\frac{1}{n\left(\mu^{2}\right)}\right) \sum_{i, j=1}^{n} \frac{1}{\left(1+\frac{\xi_{i j}}{\mu}\right)^{2}}\right]$

For controlled experimentation where error percentage is minimum $\xi_{\mathrm{ij}}$ is negligible compared to mean $(\mu)$.

Thus $\left(1+\frac{\xi_{i j}}{\mu}\right) \approx 1$

Hence Equation 4 is reduced to

$S / N=20 \log \mu$
The above equation is simple and dependent on mean value $(\mu)$ only, thus minimizing any uncertainty in readings. The calculated $\mathrm{S} / \mathrm{N}$ ratio from Equation 6 is shown in (Table 10). The $\mathrm{S} / \mathrm{N}$ ratios calculated from both the equations are nearly equal. Thus assuming non variance of mean $\mathrm{S} / \mathrm{N}$ ratios can be evaluated based on the simplified Equation 6 with reduced dependence on experimental uncertainty.

The modified Equation 6 is well applicable for very limited (even single) trial experimentation where collection of multiple trial results is not feasible due to cost involved or robustness of the experimentation on full scale structures. However an error analysis is performed to explore the extent of error margin which provides an understanding of the effect of different parameters in control of the error due to any loss of consideration for the variation in choosing an optimal and robust setting.

\section{Error Analysis}

From Equation 4 the following equation is deduced.

$S / N=(20 \log \mu)+\left(10 \log \frac{n}{\sum_{i, j=1}^{n} \frac{1}{\left(1+\frac{\xi_{i j}}{\mu}\right)^{2}}}\right)$

$S / N=(20 \log \mu)+\left(10 \log \frac{n}{\sum_{i, j=1}^{n} \frac{1}{\left(1+\xi_{r}\right)^{2}}}\right)$

Where $\left(\xi_{r}=\frac{\xi_{i j}}{\mu}\right)$ is the relative error w.r.t. mean.

In Equation 8 the term in the first parenthesis provides the contribution of mean to the signal to noise ratio and the term in the second parenthesis is the contribution of sample size and relative error in evaluation of signal to noise ratio. The error analysis is shown in Table 11. For expected error upto $15 \%$ employment of Equation 6 may yield a maximum deviation in signal to noise ratio of -1.41 to 1.21 . For higher error margin of $50 \%$ the deviation range in signal to noise 
Table 10. Comparative $\mathrm{S} / \mathrm{N}$ ratio.

\begin{tabular}{cccc}
\hline Experiment No & From Equ (1) S/N Ratio (dB) & From Equ (6) S/N Ratio (dB) & Deviation (eqn 1-equ 6) \\
\hline 1 & 14.29 & 14.32 & -0.03 \\
2 & 19.45 & 19.46 & -0.01 \\
3 & 21.58 & 21.58 & 0.00 \\
4 & 24.76 & 24.76 & 0.00 \\
5 & 13.99 & 13.99 & 0.00 \\
6 & 19.46 & 19.46 & 0.00 \\
7 & 21.57 & 21.58 & -0.01 \\
8 & 24.66 & 24.66 & 0.00 \\
9 & 13.97 & 13.98 & -0.01 \\
10 & 19.07 & 19.08 & -0.01 \\
11 & 21.47 & 21.47 & 0.00 \\
12 & 24.61 & 24.61 & 0.00 \\
14 & 12.43 & 12.46 & -0.03 \\
16 & 18.38 & 18.38 & 0.00 \\
\end{tabular}

Table 11. Error analysis of $\mathrm{S} / \mathrm{N}$ ratio.

\begin{tabular}{cc}
\hline$\xi_{\mathbf{r}}($ as $\%$ of $\mu)$ & Deviation Range in $\mathbf{S} / \mathbf{N}$ ratio \\
\hline 5 & -0.445 to 0.424 \\
10 & -0.915 to 0.828 \\
15 & -1.412 to 1.214 \\
20 & -1.938 to 1.584 \\
25 & -2.498 to 1.938 \\
30 & -3.098 to 2.279 \\
35 & -3.742 to 2.607 \\
40 & -4.437 to 2.923 \\
45 & -5.193 to 3.227 \\
50 & -6.020 to 3.522 \\
\hline
\end{tabular}

ratio increases upto -6.02 and +3.52 (Table 11 ). Hence the applicability of Equation 6 for controlled error is established.

The actual deviations which are found from (Table 10) fall within the range of (Table 11). In practice the deviation should be well within the maximum and minimum range (Table 11). It is because the errors $\left(\xi_{\mathrm{r}}\right)$ in any physical experimentation is not all positive or negative but a balance of the positive and negative attributes and the sum total of all relative errors is zero.

In derivation of the equation 6 the assumption is made for controlled experimentation where the error percentage is expected to have minimum value. Thus the equation is valid for controlled condition of experimentation with advantage of application in limited trial experimentation due to infeasibility of collecting multiple data sets. However the error analysis provides the limits of error in $\mathrm{S} / \mathrm{N}$ ratios against the relative error percentage. Hence application of the modified equation may be left to the judgments of the concerned persons depending on the type of experimentation, control over the factors in laboratory or in site and the limits upto which the error can be allowed.

\section{Conclusions}

- Taguchi optimization technique to understand the effect of powder material and dose of super-plasticizer on the relative flow index of fresh self-compacting mortar is explored in this paper. The analysis reveals degree of significance of the powder content and dose of super-plasticizer in controlling the relative flow value. It is found that super-plasticizer to powder ratio has extremely significant effect over powder to fine aggregate ratio in controlling the desired flow response. The interaction of the two factors is found to have considerable effect on the response. It is observed that a minimum powder to fine aggregate ratio of $55 \%$ should be maintained to achieve the desired flow behavior. Although higher super-plasticizer content upto 2.5\% increases the relative flow index, the associated risk of segregation restricts the super-plasticizer dose between $1.5 \%$ to $2 \%$. Thus the Taguchi method or criterion of $\mathrm{S} / \mathrm{N}$ ratios along with the ANOVA interaction analysis is suggested to find the optimal recipe;

- A modified approach for evaluation of signal to noise ratio based on the concept of error balancing property of mean (an important central tendency) is proposed. The modified equation involves only the mean value of the readings and thus excludes any effect of variation in reading due to experimental uncertainty. The modified equation is simple and well applicable for experimentation under controlled environment. Otherwise if the non-variance of mean is assumed for uncontrolled experimentation the equation expresses signal to noise ratio on zero error scale. The approach is also well applicable for optimization of experimentation where limited (even one) trial is involved and collection of multiple trial results is not feasible. Such a condition may arise at site for costly experimentation on full scale structures. The error analysis provides clear insight into individual effect of combination of mean, sample size and relative error on signal to noise ratio. 


\section{Acknowledgements}

The constant motivation of the Director, Central Mechanical Engineering Research Institute, Durgapur (CSIR-CMERI) in writing the manuscript is gratefully acknowledged. The authors are also grateful to Dr. Reeta

\section{References}

1. European Federation which Unites National Associations and Companies - EFNARC. Specification and Guidelines for SelfCompacting Concrete. London; Feb 2002.

2. Ozawa K, Maekawa K, Kunishima M and Okamura H. Development of High Performance Concrete based on the Durability Design of Concrete Structures. Proceedings of the Second East-Asia and Pacific Conference on Structural Engineering and Construction (EASEC-2). 1989; 1:445-450.

3. Okamura $\mathrm{H}$ and Ouchi M. Self-Compacting Concrete. Journal of Advance Concrete Technology. 2003; 1:5-15. http://dx.doi. org/10.3151/jact.1.5

4. Domone PL. Self-Compacting Concrete: An analysis of 11 years of case studies. Cement and Concrete Composites. 2006 Feb; 28:197-208. http://dx.doi.org/10.1016/j. cemconcomp.2005.10.003

5. Das D, Gupta VK and Kaushik SK. Effect of Maximum Size and Volume of Coarse Aggregate on the Properties of SCC. The Indian Concrete Journal. 2006 Mar; 80(3):53-56.

6. Degirmenci N and Yilmaz A. Use of pumice fine aggregate as an alternative to standard sand in production of light weight cement mortar. Indian Journal of Engineering \& Material Sciences. 2011 Feb; 18:61-68.

7. Cazalla O, Sebastian E, Cultrone G, Nechar M and Bagur MG. Three way ANOVA interaction analysis and ultrasonic testing to evaluate air lime mortars used in cultural heritage conservation projects. Cement and concrete research. 1999; 29:1749-1752. http://dx.doi.org/10.1016/S0008-8846(99)00158-1

8. Turkmen I and Findik SB. Several properties of mineral admixtured light weight mortars at elevated temperatures. Fire and materials. 2010. http://dx.doi.org/10.1002/fam.1030

9. Tate M. The most important property of cement lime mortar in masonry construction. In: International building lime symposium; 2005; Orlando. Orlando; 2005.

10. Das D and Chatterjee A. A Comparison of hardened properties of fly-ash based self- compacting concrete and normally compacted concrete under different curing conditions. Magazine of Concrete Research. 2012 Feb; 64(2):129-141. http://dx.doi.org/10.1680/macr.10.00118

11. Sahamaran M, Christianto HA and Yaman IO. The effect of chemical admixtures and mineral additives on the properties of self compacting mortars. Cement and concrete composites. 2006; 28(5):432-440. http://dx.doi.org/10.1016/j. cemconcomp.2005.12.003

12. Turk Kazim. Viscosity and hardened properties of self compacting mortars with binary and ternary cementitious blends of fly ash and silica fume. Construction and Building Materials. 2012; 37:326-334. http://dx.doi.org/10.1016/j. conbuildmat.2012.07.081
Das, Scientist, CSIR-CMERI, and Prof. (Dr.) Anindya Chatterjee, IIT Kharagpur for their constant support and encouragement. The enormous help of Sri Dayamay Bouri and Sri Krishnendu Banerjee in preparing the manuscript is gratefully acknowledged.

13. Bouzoubaa $\mathrm{N}$ and Lachemi M. Self compacting concrete incorporating high volumes of class F fly ash: Preliminary results. Cement and Concrete Research. 2001; 31(3):413-420. http://dx.doi.org/10.1016/S0008-8846(00)00504-4

14. Tan $\mathrm{O}$ and Zaimoglu AS. Taguchi approach for investigation of the setting times on cement based grouts. Indian Journal of Engineering and Materials Sciences. 2004; 11(1):63-67.

15. Hinislioglu $\mathrm{S}$ and Bayrak OU. A robust approach for evaluating modulus of elasticity of pavement concrete. Indian Journal of Engineering and Materials Sciences. 2005; 12(2):111-116.

16. Chaulia PK and Das R. Process Parameter Optimization for Fly ash Brick by Taguchi Method. Materials Research. 2008; 11(2):159-164. http://dx.doi.org/10.1590/ S1516-14392008000200008

17. Bureau of Indian Standards - BIS. Indian Standard Code of Practice IS 3812: Specification for Fly Ash for use as Pozzolona and Admixture. New Delhi: BIS; 1981.

18. Bureau of Indian Standards - BIS. Indian Standard Code of Practice IS 15388: Silica- Fume-Specification. New Delhi: BIS; 2003.

19. Code of American Society for Testing and Material. ASTMC 494: Standard Specification for Chemical Admixtures for Concrete. 1962.

20. Bureau of Indian Standards - BIS. Indian Standard Code of Practice IS 9103: Concrete Admixtures- Specifications. New Delhi: BIS; 1999.

21. Bureau of Indian Standards - BIS. Indian Standard Code of Practice IS 1791: General requirements for batch type concrete mixers. New Delhi: BIS; 2005.

22. Petersson O. Limestone powder as filler in self-compacting concrete-Frost resistance and compressive strength Proceedings of the Second International Symposium on selfcompacting conrete. 2001; 277-284.

23. Uchikawa H, Hanehara S and Sawaki D. The role of steric repulsive force in the dispersion of cement particles in fresh paste prepared with organic admixture. Cement and Concrete Research. 1997; 27:37-50. http://dx.doi.org/10.1016/S00088846(96)00207-4

24. Sugiyama T, Sugamata $\mathrm{T}$ and Ohta A. The effects of high range water reducing agent on the improvement of rheological properties. Proceedings of the seventh CANMET/ ACI International conference on superplasticizers and other chemical admixtures in concrete. ACI S P-217. 2003; 343-360.

25. Nepomuceno M, Oliveira L and Lopes SMR. Methodology for mix design of the mortar phase of self compacting concrete using different mineral additions in binary blends of powders. Construction and Building Material. 2012; 26(1):317-326. http://dx.doi.org/10.1016/j.conbuildmat.2011.06.027

Appendix 1. List of notations.

$\mathrm{S} / \mathrm{N}$ - Signal to Noise ratio.

$\Gamma_{\mathrm{m}}$ - Relative flow index.

$\mathrm{Y}_{\mathrm{ij}}$ - Reading of $\mathrm{i}^{\text {th }}$ trial of $\mathrm{j}^{\text {th }}$ reading. $\mathrm{n}$ - No of reading.

$\xi_{\mathrm{ij}}$ - Error of $\mathrm{i}^{\text {th }}$ trial of $\mathrm{j}^{\text {th }}$ reading.

$\xi_{\mathrm{r}}$ - Relative error. 